\title{
Infection of Mesothelial Cells with Human Herpes Virus 8 in Human Immunodeficiency Virus-Infected Patients with Kaposi's Sarcoma, Castleman's Disease, and Recurrent Pleural Effusions
}

Peter Bryant-Greenwood, M.D., Lynn Sorbara, Ph.D., Armando C. Filie, M.D., Richard Little, M.D., Robert Yarchoan, M.D., Wyndham Wilson, M.D., Mark Raffeld, M.D., Andrea Abati, M.D.

Laboratory of Pathology (PB-G, LS, ACF, MR, AA), HIV and AIDS Malignancy Branch (RL, RY), and Experimental Transplantation and Immunology Branch (WW), National Institutes of Health, National Cancer Institute, Bethesda, Maryland

Recurrent pleural effusions are common complications of hospitalized patients with human immunodeficiency virus (HIV) infection and may pose difficult diagnostic dilemmas. A common cause of recurrent pleural effusions in up to $30 \%$ of HIVseropositive patients is pulmonary involvement by Kaposi's sarcoma, a human herpesvirus 8 (HHV 8)related neoplasm. The pathogenesis of these effusions is unclear. These recurrent effusions, although benign, have shown significant mesothelial atypia/ reactive changes of uncertain etiology. We attempted to evaluate these effusions morphologically and molecularly for the presence of HHV 8, with particular attention to mesothelial cells. All recurrent pleural effusions, as defined by any effusion tapped for cytological examination on more than two occasions, in HIV-positive patients at the National Institutes of Health were examined from 1998 to the present. Cases were stratified according to patients with and without histologically confirmed HHV 8 disease manifestations. Five patients with HHV 8 diseases (four with disseminated Kaposi's sarcoma and one with Castleman's disease) were identified. As a control group, five effusions from HIV-seropositive patients without known HHV 8-related diseases were identified. Cytological examination of effusions in patients with HHV 8-related diseases demonstrated atypical/markedly reactive mesothelial cells accompanied by a polymorphous background of lymphocytes. Molecular studies for B- and T-cell clonality in microdis-

Copyright ( $\odot 2003$ by The United States and Canadian Academy of Pathology, Inc.

VOL. 16, NO. 2, P. 145, 2003 Printed in the U.S.A.

Date of acceptance: December 3, 2002.

Address reprint requests to: Andrea Abati, M.D., National Cancer Institute, Cytopathology Section, Building 10, Room 2A19, Bethesda, MD; fax: 301-402-2585; e-mail: abatia@mail.nih.gov.

DOI: 10.1097/01.MP.0000052374.61768.79 sected whole samples showed no definitive clones in these cases. Conversely, polymerase chain reaction (PCR) studies for the HHV 8 virus was positive in these samples. PCR studies on pure populations of microdissected mesothelial cells from the HHV 8-related effusions were positive for HHV 8 sequences, whereas those from HIV patients with non-HHV 8 related diseases were negative. Immunohistochemistry for HHV 8 (monoclonal antibody to latent nuclear antigen (LNA-1; ORF-73) on cellblock material demonstrated scattered positive mesothelial cells in three of the five cases of HHV 8-associated effusions. HHV 8 has been recently implicated in the pathogenesis of Kaposi's sarcoma and primary effusion lymphoma. Mesothelial cells in recurrent pleural effusions from patients with Kaposi's sarcoma and Castleman's disease appear to be infected with HHV 8. Additional studies need to be done to define the role of mesothelial cell infection in the pathogenesis of these HHV 8-associated effusions and define the prognostic significance.

KEY WORDS: Castleman's disease, HHV 8, HIV, Kaposi's sarcoma, Mesothelial cells, Pleural effusions. Mod Pathol 2003;16(2):145-153

Recurrent pleural effusions can pose a major diagnostic dilemma in HIV positive patients. Although only $2 \%$ of HIV-seropositive individuals overall have such effusions, this figure can climb to up to $27 \%$ in the hospitalized AIDS population $(1,2)$. Between $50 \%$ and $70 \%$ of the effusions in HIVseropositive individuals are infectious in nature (3). Streptococcus pneumoniae and Staphylococcus aureus are the most common infectious agents, followed by Mycobacterium species, Nocardia species, Pneumocystis carinii, and various fungi $(3,4)$. Thirty percent of effusions in HIV-seropositive patients 
are related to pleural or pulmonary involvement by Kaposi's sarcoma, and the final $5 \%$ to $10 \%$ of effusions are either neoplastic in nature, including primary effusion lymphomas, or of unknown etiologies (4).

The clinical and radiological features of pulmonary Kaposi's sarcoma are often difficult to distinguish from infection and other neoplastic processes (5-7). It has become increasingly apparent that the majority of tumors arising in HIV-infected patients have a viral etiology. A recently described herpesvirus, called Kaposi's sarcoma-associated herpes virus or human herpes virus 8 (HHV 8), has been identified as the etiologic agent for Kaposi's sarcoma, primary effusion lymphoma, and most cases of multicentric Castleman's Disease $(8,9)$. The virus has been identified in the spindle cells of Kaposi's sarcoma. In most spindle cells, the virus is in a latent phase and expresses latent nuclear antigen (LNA-1; 10-12). In multicentric Castleman's disease the virus has been identified in plasmacytoid B cells in the mantle zone of lymphoid follicles and interfollicular areas $(11,13-15)$. These cells are infected with the virus in either its latent or lytic phase, thus expressing either latent nuclear antigens or the viral homolog of human interleukin-6 (vIL-6), respectively $(10,11,13-15)$. In primary effusion lymphoma, the malignant cells have been shown to be infected with HHV 8 in both the latent and lytic phases (16-18). Circulating B cells, T cells, and monocytes have all also been shown to contain latent virus in infected individuals $(16,17,19,20)$.

Recurrent pleural effusions are a clinical problem in patients with HHV 8-related diseases, particularly those with pulmonary involvement by Kaposi's sarcoma (2). Interestingly, it has been difficult to identify actual Kaposi's spindle cells in the cytologic evaluation of these samples, with only a single case report substantiating their presence via immunohistochemistry (21). Several theories have been popularized as to the etiologies of these effusions: thoracic duct blockage by tumor cells; decreased lymphatic drainage; and finally vascular hyperpermeability caused by the production of vascular endothelial growth factor by the tumor cells (1).

In 1999, Ascoli et al. (22) published on a series of these effusions in HIV serovariable patients with HHV 8-related diseases (Kaposi's sarcoma, multicentric Castleman's disease, and primary effusion lymphoma). They evaluated the cellular constituents of the effusions morphologically and molecularly. Morphologically, the benign effusions were characterized by numerous monocytes/macrophages and mesothelial cells (22). On the molecular level, the majority of the HHV 8-related benign effusions contained HHV 8 viral sequences in microdissected whole samples tested. Based on these findings, Ascoli et al. (22) suggested that HHV 8-re- lated effusions could be divided into two types. The first represented an atypical lymphoid infiltrate which may either have been a frank lymphoma (primary effusion lymphoma) or in the process of transforming into one. The second represented an HHV 8-related reactive intracavitary serositis, perhaps related to pleural infection with HHV 8 (22).

As the samples in the Ascoli study evaluated for HHV 8 by PCR were whole samples, it was not possible to determine which cells were infected by the virus. Peripheral blood B cells or monocytes, which have been shown to harbor the virus in infected individuals may have been responsible for the virus detection $(16-20,22)$.

This study attempts to further examine the recurrent, non-lymphomatous HHV 8-associated effusions in HIV-seropositive individuals, with particular emphasis on the mesothelial cells. The effusions were molecularly characterized for both lymphoid clonality and the presence of HHV 8 viral sequences and were compared with a series of effusions in HIV-seropositive patients with no known HHV 8 associated diseases (i.e., primary effusion lymphoma, multicentric Castleman's disease, Kaposi's sarcoma).

\section{MATERIALS AND METHODS}

All recurrent pleural effusions in HIVseropositive patients at the National Institutes of Health Clinical Center, as defined by any effusion tapped for cytological examination on more than two occasions, were examined from 1998 to the present. Cases were stratified according to patients with and without histologically confirmed systemic HHV 8 diseases of Kaposi's sarcoma or multicentric Castleman's disease. Five patients with Kaposi's sarcoma or multicentric Castleman's disease were identified: four with disseminated Kaposi's sarcoma, and one with multicentric Castleman's disease. For comparison, five HIV-seropositive patients with recurrent effusions without known HHV 8-associated diseases were identified.

Cytological examination involved evaluation of the lymphoid population, the mesothelial component and the inflammatory background.

Molecular studies were performed on archival, microdissected, cytologic material on all 10 patients. These included polymerase chain reaction (PCR) for the presence of gene rearrangements of the IgH framework III locus of B-cells; T-cell gamma receptor gene locus; HHV 8 gene sequences (open reading frame 26) on the heterogeneous effusion specimen; and HHV 8 gene sequences (open reading frame 26 ) on the microdissected mesothelial component present in all effusions as described below. 
Standard cytologic criteria were used to identify mesothelial cells (23). Mesothelial cells were microdissected by hand with a $30 \mathrm{G}$ needle in five cases, as in our experience, laser capture microdissection cannot effectively be utilized for air-dried material stained with Diff-Quik. In five cases, Patients 1, 2, 3, 4, 8 (Table 1), where Pap-stained material was available, a two-step laser capture microdissection protocol was utilized in which all non-mesothelial cells were removed first, leaving behind only cells which were morphologically identifiable as mesothelial cells. The laser then harvested the remaining mesothelial cells for PCR for HHV 8 gene sequences (24-27).

On the Diff-Quik stained slides, the mesothelial cells, even in the presence of nuclear atypia, retained the classic bi-phasic "endoplasmicectoplasmic" demarcation of the cytoplasm. This was visible in most mesothelial cells as an area of perinuclear eosinophilia and peripheral basophilia. This staining characteristic is due to a significant density of intermediate filaments around the nucleus. Cells lacking this cytoplasmic appearance were not microdissected. When the cytoplasm of suspected mesothelial cells was vacuolated, simulating the cytoplasm of accompanying macrophages, the characteristic round to oval nuclei with smooth contours were used to distinguish them from the characteristically reniform-shaped nuclei with irregular contours found in macrophages. Although the aforementioned cytological criteria were also used on the Papanicolaou-stained slides, this material had the additional advantage of highlighting the finely stippled chromatin and the prominent nucleoli of the mesothelial cells.

Laser capture microdissection was performed according to the methodology outlined by Buck et al. (24). All samples, whether hand microdissected or laser microdissected, were pretreated in $20 \mu \mathrm{L}$ of Gene Releaser resin (Bioventures, Inc.), according to the manufacturer's recommendation.
GAPDH (Glyceraldehyde Phosphate Dehydrogenase) gene was used as a control to assess the sample quality of DNA for amplification. The oligonucleotide primers used in this assay and conditions were reported by Otsuki et al. (25).

Amplification of the IgH FR III B-cell gene involved primer sets and conditions outlined by Segal et al. (26), and T-cell receptor PCR for T-cell gamma receptor gene clonality was performed according to the methodology of McCarthy et al. (27). PCR for HHV 8 virus sequences (open reading frame 26) used a protocol devised by Otsuki et al. (25). The negative control for all aforementioned assays consisted of water and PCR mixture devoid of template. All reactions were carried out at $100-\mu \mathrm{L}$ volumes. Taq polymerase (Applied Biosystems) plus TaqStart antibody (Clontech) was used for all reactions. PCR products from HHV 8 and GAPDH PCR were separated by $2 \%$ agarose gel electrophoresis, whereas PCR products from T-cell and B-cell clonality were separated by $16 \%$ polyacrylamide gel electrophoresis. All gels were stained with ethidium bromide before visualization and photography.

For the specific PCR determination of HHV 8, samples were assayed in accordance with College of American Pathologist regulations, i.e., unknown samples were prepared first followed by positive control(s), and finally, the template-negative control. All samples were analyzed simultaneously within the same assay using the same master mix solution. No bands or traces of bands were visualized in either the template-negative control or any of the negative samples that might suggest nonspecific amplification or amplicon contamination.

Immunohistochemistry for HHV 8, ORF 73 latent nuclear antigen-1, was performed on formalin fixed paraffin-embedded cellblock material for all patients where available. Five-micrometer sections were cut and then placed on charged glass slides. Immunohistochemistry was performed using the avidin-biotin-peroxidase complex (Vector Labora-

TABLE 1. HHV-8 Diseases

\begin{tabular}{|c|c|c|c|c|c|c|c|}
\hline \multirow{2}{*}{ Patient/Diagnosis } & \multirow{2}{*}{ Lymphocytes } & \multirow{2}{*}{ Mesothelial Cells } & \multirow{2}{*}{ T-Cell } & \multirow{2}{*}{ B-Cell } & \multicolumn{3}{|c|}{ HHV-8 } \\
\hline & & & & & Total Effusion & Mesothelial Cells & Immunohistochemistry \\
\hline 1/Kaposi's Sarcoma ${ }^{1}$ & Polymorphous & Reactive/Atypical & - & - & + & + & + \\
\hline 2/Kaposi's Sarcoma ${ }^{1}$ & Polymorphous & Reactive/Atypical & - & - & + & + & + \\
\hline 3/Kaposi's Sarcoma ${ }^{1}$ & Atypical & Reactive/Atypical & - & $?$ & + & + & - \\
\hline 4/Kaposi's Sarcoma ${ }^{1}$ & Polymorphous & Reactive/Atypical & - & - & + & + & + \\
\hline 5/Castleman's Disease & Polymorphous & Reactive/Atypical & - & - & + & + & - \\
\hline \multicolumn{8}{|l|}{ Non-HHV-8 Processes } \\
\hline 6/Disseminated MAI & Polymorphous & Normal/Reactive & Oligoclonal & - & - & - & - \\
\hline 7/Aspergillosis & Acute inflammation & Normal/Reactive & - & - & - & - & - \\
\hline 8/Disseminated $\mathrm{MAI}^{1}$ & Polymorphous & Normal/Reactive & - & - & - & - & - \\
\hline 9/DLBCL* & Polymorphous & Normal/Reactive & - & - & - & - & - \\
\hline 10/DLBCL & Atypical & Normal/Reactive & - & + & - & - & - \\
\hline
\end{tabular}


tories, Berkley CA). Microwave antigen -antigen (LNA-1)ORF-73 of HHV 8 (Advanced Biotechnologies, Columbia, MD) at 1:500dilution was applied as per the manufacturer's recommendations. Negative controls and appropriate positive controls were employed throughout.

Two patients from the HHV 8-related disease cohort subsequently died and were autopsied at the NIH. Multiple sections of lung and pleura were fixed in formalin and submitted for histologic examination. Immunohistochemistry for HHV 8 was performed to assess staining in mesothelial cells on samples from these autopsies.

\section{RESULTS}

\section{Cytology}

Reactive/atypical mesothelial cells were identified in variable numbers in all five HHV 8-related disease-associated effusions. The reactive/atypical features in mesothelial cells included: prominent multinucleation, variable nuclear size, cell-in-cell formation and numerous mitoses (Fig. 1A-B). Lymphoid populations were mixed (acute and chronic) and benign appearing in all 10 cases except 2: 1 in which a patient with HIV was known to have a large B cell lymphoma and the cells in the effusion had the appropriately malignant morphology; and 1 in which a patient with disseminated Kaposi's had atypical lymphoid cells which were suspicious for, but non-diagnostic by PCR for a clonal population. (See below.)

\section{Immunohistochemistry}

Cell blocks were available on five of five effusion samples from patients with HHV 8 - related diseases. Three of five showed nuclear immunoreactivity in the mesothelial cells and mononuclear inflammatory cells for HHV 8 LNA (Fig. 2). Cell blocks of effusions from four of the five HIV-seropositive patients with non-HHV 8-related diseases had cell blocks available for immunoperoxidase studies. The mesothelial cells and mononuclear inflammatory cells were consistently non- immunoreactive for HHV 8 LNA. Visceral pleural mesothelial cells were also identified in the autopsy material in two of the patients in the HHV 8-associated disease cohort (Fig. 3). Immunohistochemistry for HHV 8 LNA in autopsy sections confirmed the presence of widespread pleural-pulmonary disease of Kaposi's sarcoma. However, atypical mesothelial cells both overlying and away from the Kaposi's sarcoma lesions were only equivocally positive for HHV 8 LNA.

\section{Molecular Studies}

All samples tested showed amplifiable DNA as per GAPDH testing (Fig. 4). Molecular studies for B and T cell clonality and HHV 8 gene sequences, as described above, were performed on microdissected whole samples on all 10 cases.

Of the HIV-seropositive samples in patients with non-HHV 8-related diseases, no evidence of HHV 8 DNA was identified by PCR. One of the five samples showed a T-cell clone. This clone was identified in a patient with disseminated mycobacterium avium intracellulare, and is not an unusual non-neoplastic immunological response to this disease (Sorbara L, personal communication) One of these five patients exhibited a B-cell clone that was consistent with his malignant cytology and history of large B-cell lymphoma.

Of the patients with HHV 8-related diseases, evidence of HHV 8 DNA was present by PCR in five of five samples tested. No evidence of T-cell clones was identified in five of five samples tested. No definitive evidence of B cell clones were identified in four of five samples. In one sample a band suspicious, but not diagnostic, of a B-cell clone was identified. This was identified in the effusion sample with lymphoid atypia. Unfortunately, this patient was lost to follow up.

PCR studies for the open reading frame 26 of HHV 8 DNA were performed on microdissected mesothelial cells from all 10 samples (Fig. 5). No HHV 8-related sequences were identified in the mesothelial cells of the HIV-seropositive patients without HHV 8-related diseases. Conversely, bands for HHV 8-related sequences were strongly present in microdissected mesothelial cells from five of five effusion samples (100\%) from patients with HHV 8 -related diseases (Fig. 5).

\section{DISCUSSION}

Recurrent pleural effusions in the HIVseropositive population can pose diagnostic difficulty because of the large spectrum of possible infectious and neoplastic etiologies (1). Kaposi's sarcoma, multicentric Castleman's disease, and primary effusion cavity lymphoma, HHV 8-related diseases that are much higher in incidence in the HIV-seropositive population than in the general public, have been shown to cause recurrent effusions in this population (28). Although the cytologic determination of primary effusion lymphoma can be easily made, the effusions caused by Kaposi's sarcoma and multicentric Castleman's disease have nonspecific cellular constituents (22). Further examination on our part revealed the mesothelial cells in these effusions to have atypical morphologic features. Although there are reports of spindle cell lines being derived from pleural effusions in 


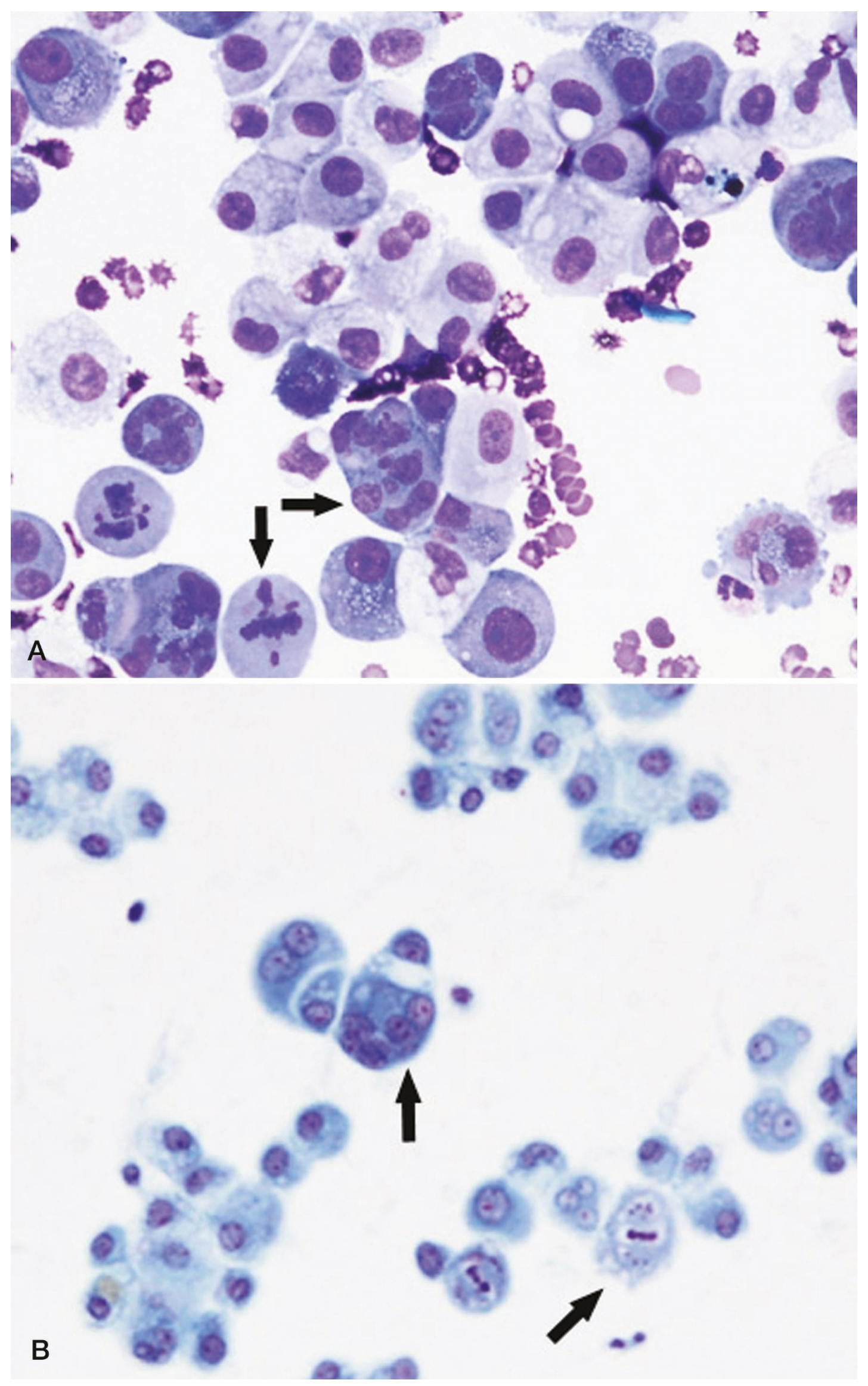

FIGURE 1. A, atypical mesothelial cells with altered nuclear-to-cytoplasmic ratios, irregular nuclei, and bizarre multinucleated forms (Diff-Quik, $200 \times$ ). B, atypical mesothelial cells in a background of small lymphocytes and histiocytes (Papanicolaou, 200×). 


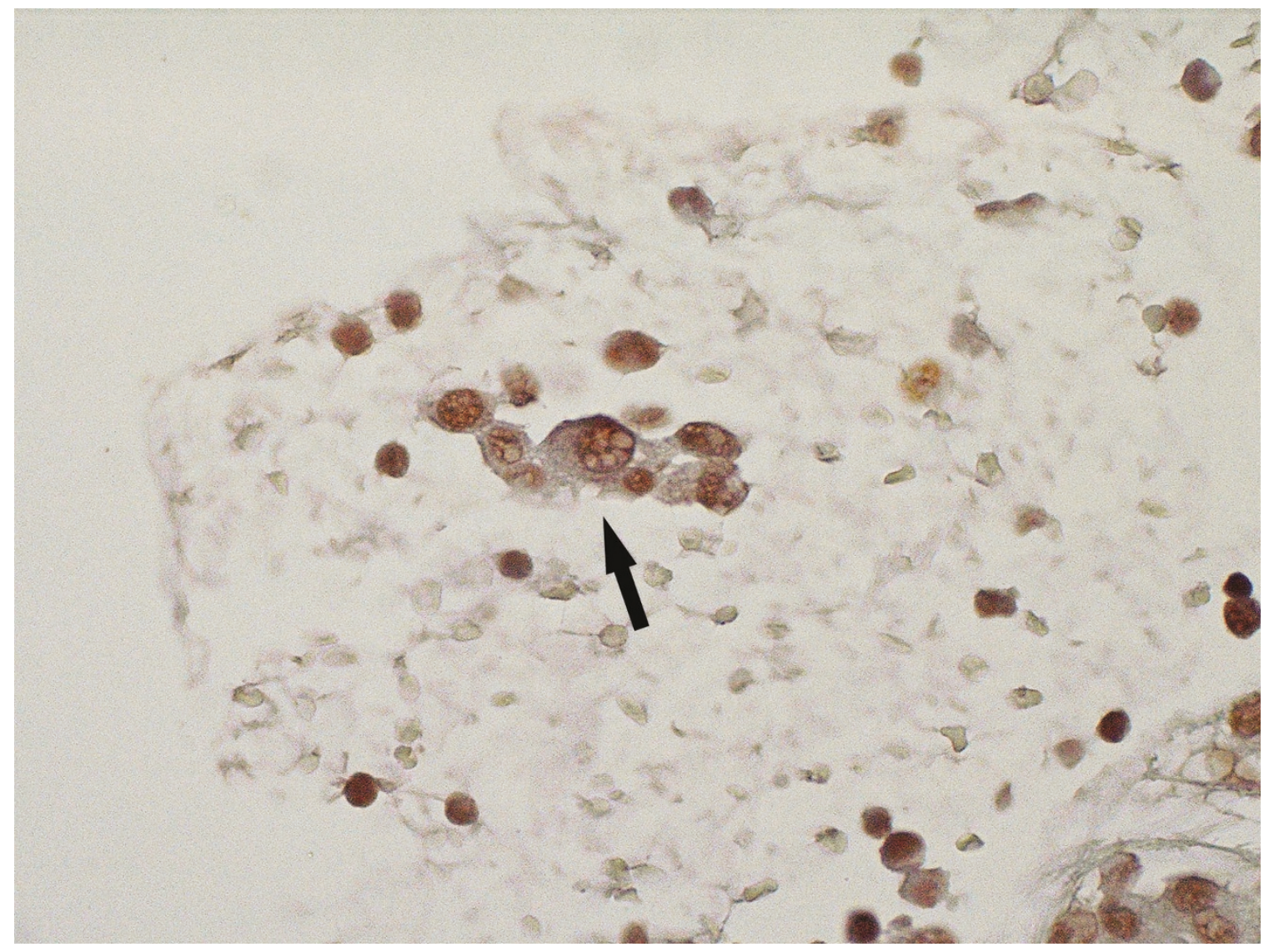

FIGURE 2. HHV-8 immunohistochemistry: positive staining of mesothelial cells in cell block material $(200 \times)$.

patients with pulmonary involvement with Kaposi's sarcoma, there is only a single case report claiming to positively identify neoplastic spindle cells in the effusion $(21,29,30)$. The findings herein raise the possibility that, in fact, effusion-derived cell lines with spindled morphology may actually represent mesothelial-derived lines, as mesothelial cells may have a biphasic morphology.

Never-the-less recurrent effusions associated with Kaposi's and multicentric Castleman's may portend a relatively poor prognosis (2). Before the development of highly active anti-retroviral therapy, the median survival for HIV-seropositive patients with HHV 8 associated effusions was 205 days, compared with 338 days for infectious and malignant effusions in HIV patients without HHV 8-related diseases (31). We show here that effusions related to HHV 8 disease can have a distinct morphology that includes numerous atypical mesothelial cells in a polymorphous lymphoid background. As the etiology of the atypia in these cells was not obvious and was similar to viral changes we noted previously in unrelated samples, we set out to evaluate these mesothelial cells by PCR and immunohistochemistry for the potential presence of HHV 8.

Our positive PCR results for HHV 8 viral sequences in microdissected atypical mesothelial cells supports several points. First and foremost, it suggests that there is a direct infection of the mesothelial cells with HHV 8. This infection may initiate a serositis that contributes to the pathogenesis of these recurrent effusions. Second, this direct infection most likely is the causative factor of the atypia and reactive changes noted in these cells. Additionally, it remains speculative as to the potential role of mesothelial infection by HHV 8 and the development of HHV 8-related primary effusion lymphoma. Although HHV 8-positive lymphomas have been described as solid lesions in HHV 8 and non-HHV 8 patients $(25,32,33)$, it remains enticing to speculate on the role of infection of mesothelial cells by HHV 8 and the secondary serositis as a factor in the eventual pathogenesis of primary effusion lymphoma. Our one patient with HHV 8 and atypical lymphoid cells that were suspicious, but not diagnostic for a B cell clone by PCR was, unfortunately, lost to follow up.

The initial evaluation of these effusions revealed the cellular constituents to be composed of a large number of lymphocytes (T-cells more than B-cells), monocytes, and reactive mesothelial cells (22). PCR on microdissected whole samples tested positively for HHV 8 viral sequences by PCR (22) Although we 


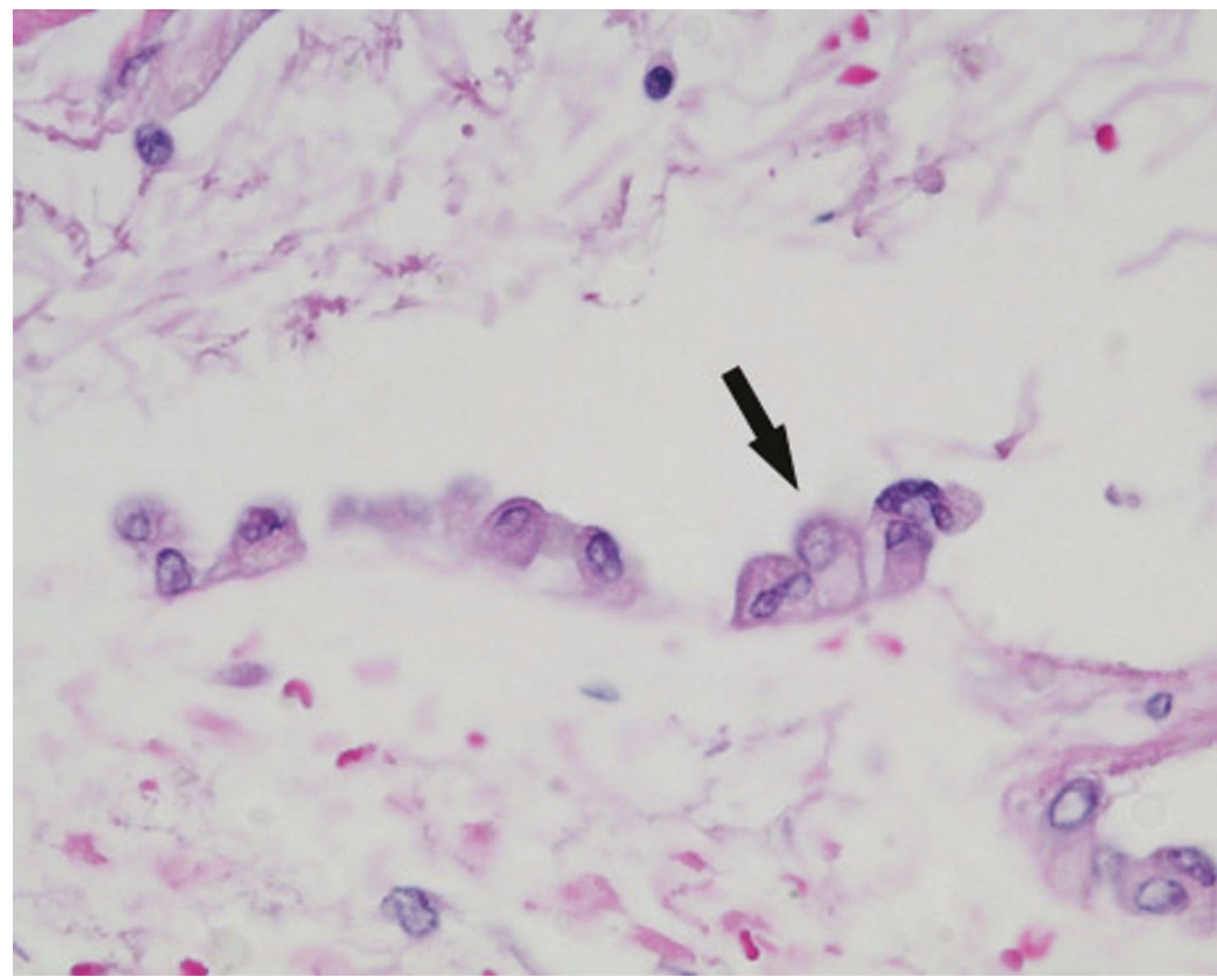

FIGURE 3. Atypical mesothelial cells in autopsy specimen (hematoxylin and eosin, 200×).

described as "atypical" what Ascoli et al. (22) referred to as "reactive changes" in the mesothelial cells of these effusions, this issue is fairly irrelevant.

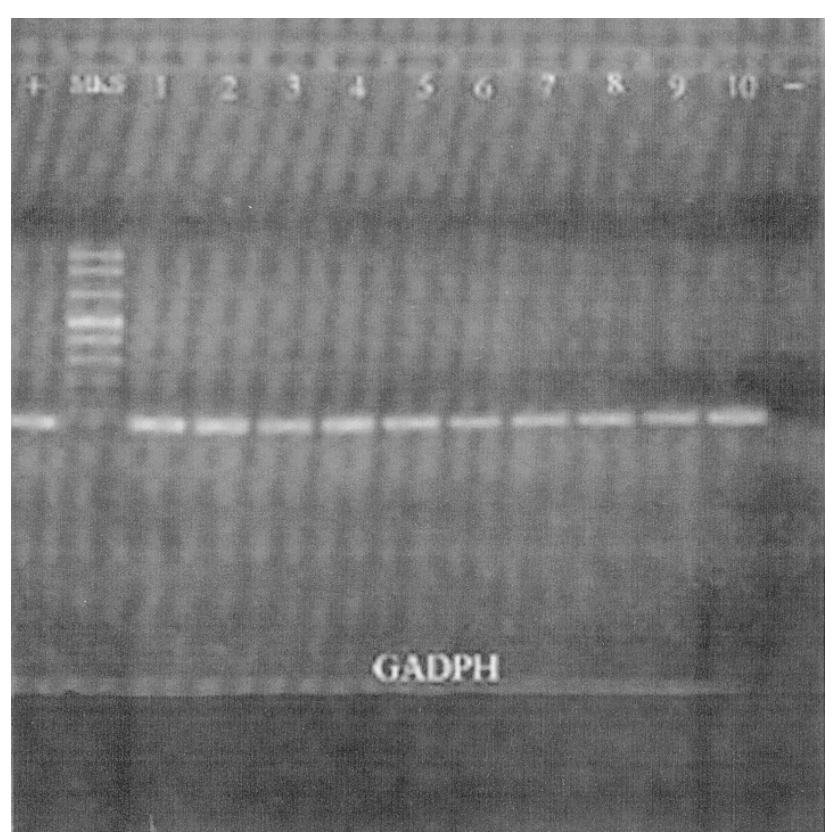

FIGURE 4. GAPDH control: All 10 cases demonstrate positive amplification.
Mesothelial cells are known to exhibit a significant degree of variability that is similar in benign, reactive and malignant processes.

HHV 8 infected cells produce various cytokines, such as a viral IL-6, an indicator of lytic infection, that has been shown to induce proliferation of primary effusion lymphoma cells (34). Additionally, the presence of Epstein Barr virus has been associated with primary effusion lymphoma in a significant proportion of cases and has been theorized to be a co-factor in the pathogenesis of this neoplasm in such cases, acting along with HHV 8 (35). Clearly, further studies are warranted evaluating the viral phases of HHV 8 within the mesothelial cells in these benign and malignant effusions as well as potentially the EBV status of these cells. Hopefully studies such as this will further elucidate the nature of these benign and potentially malignant effusions in this unfortunate patient population. Recent progress in antiretroviral therapy as well as improved supportive care should lead to better survival rates in AIDS in the future. Unfortunately, this progress may be associated with a growing number of patients with AIDS who are susceptible to AIDS related malignancies and HHV 8-related complications. 


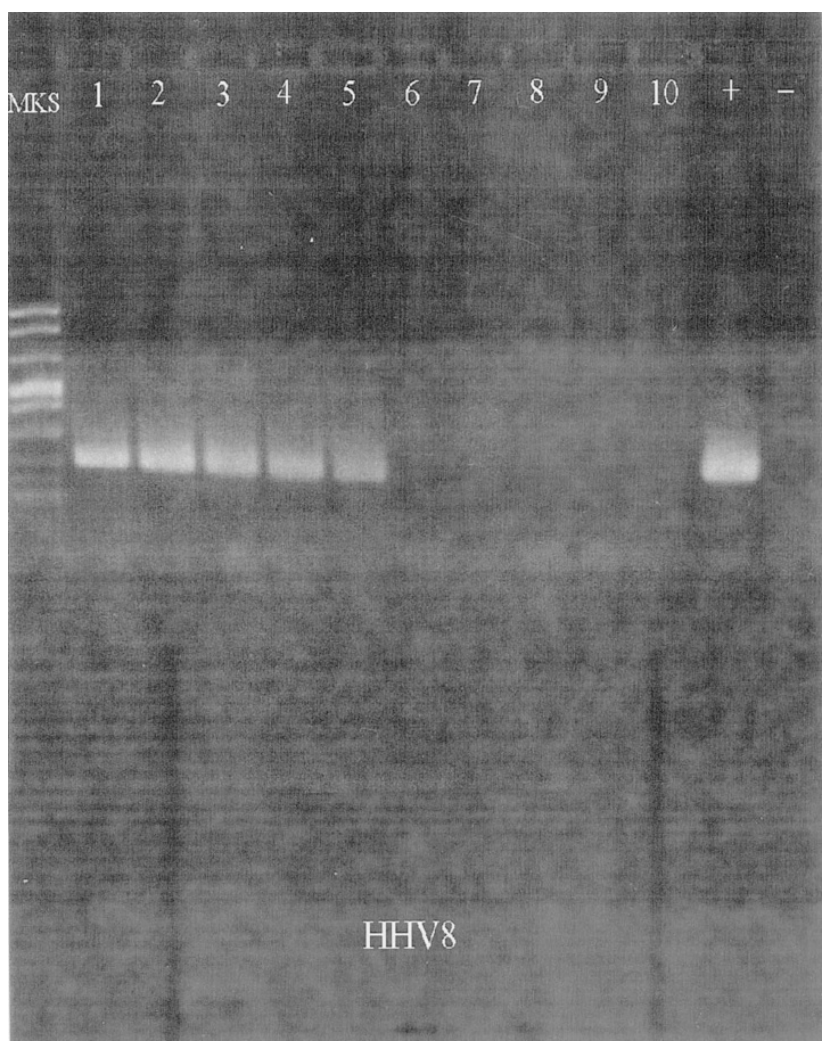

FIGURE 5. HHV-8 PCR on microdissected mesothelial cells: Lanes 1 through 5 demonstrate amplification in all patients with either Kaposi's Sarcoma or Castleman's disease. Lanes 6 through 10 show no amplification in the microdissected mesothelial cells from HIV+ patients with no known HHV 8-related disease processes.

Precise classification of the non-neoplastic effusions encountered in this population may become critical to patient management.

\section{REFERENCES}

1. Light RW, Hamm H. Pleural disease and acquired immune deficiency syndrome. Eur Respir J 1997;10:2638-43.

2. Afessa B. Pleural effusions and pneumothoraces in AIDS. Curr Opin Pulm Med 2001;7:202-9.

3. Soubani AO, Michelson MK, Karnik A. Pleural fluid findings in patients with AIDS: correlation with concomitant pulmonary disease. South Med J 1999;92:400-3.

4. Miller RF, Howling SJ, Ried AJ, Shaw PJ. Pleural effusions in patients with AIDS. Sex Transm Infect 2000;76:122-5.

5. Ognibene FP, Steis RG, Macher AM, et al. Kaposi's sarcoma causing pulmonary infiltrates and respiratory failure in AIDS. Ann Intern Med 1985;102:471-5.

6. Huang L, Schnapp LM, Gruden JF, et al. Presentation of AIDS-related pulmonary Kaposi's sarcoma diagnosed by bronchoscopy. Am J Respir Crit Care Med 1996;153:1385-90.

7. Pompili CG, Dellafiore L, Alineri S, et al. AIDS-related pulmonary Kaposi's sarcoma: role of high-resolution computerized tomography. Radiol Med 1998;96:318-24.

8. Chang Y, Cesarman E, Pessin MS, et al. Identification of herpesvirus-like DNA sequences in AIDS associated Kaposi's sarcoma. Science 1994;266:1865-9.

9. Shulz TF. KSVH (HHV 8) infection. J Infect 2000;41:125-9.

10. Cannon JS. Nicholas J, Orenstein JM, et al. Heterogeneity of viral IL-6 expression in HHV-8 associated disease. J Infect Dis 1999;180:824-8.
11. Dupin N, Fisher C, Kellam P, et al. Distribution of human herpesvirus 8 latently infected cells in Kaposi's sarcoma, multicentric Castleman's disease, and primary effusion lymphoma. Proc Natl Acad Sci U S A 1999;96:4546-51.

12. Moore PS, Boshoff C, Weiss RA, et al. Molecular mimicry of human cytokine and cytokine response pathway genes by KSHV. Science 1996;274:1739-44.

13. Parravicini C, Corbellino M, Paulli M, et al. Expression of a virus-derived cytokine, KSHV vIL-6, in HIV-seronegative Castleman's disease. Am J Pathol 1997;151:1517-22.

14. Dupin N, Diss TL, Kellam P, et al. HHV-8 is associated with a plasmablastic variant of Castleman disease that is linked to HHV-8 positive plasmablastic lymphoma. Blood 2000; 95:1406-12.

15. Parravicini C, Chandran B, Corbellino M, et al. Differential viral protein expression in Kaposi's sarcoma-associated herpesvirus-infected diseases. Kaposi's sarcoma, primary effusion lymphoma, and multicentric Castleman's disease. Am J Pathol 2000;156:743-9.

16. Hengge UR, Ruzicka T, Tyring SK, et al. Update on Kaposi's sarcoma and other HHV 8 associated diseases. Part 2: pathogenesis, Castleman's disease, and pleural effusion lymphoma. Lancet Infect Dis 2002;2:344-52.

17. Schulz TF. KSVH/HHV 8-associated lymphoproliferations in the AIDS setting. Eur J Cancer 2001;37:1217-26.

18. Staskus KA, Sun R, Miller G, et al. Cellular tropism and viral interleukin-6 expression distinguish human herpesvirus 8 involvement in Kaposi's sarcoma, primary effusion lymphoma, and multicentric Castleman's disease. J Virol 1999; 73:4181-7.

19. Whitby D, Howard MR, Tenant-Flowers M, et al. Detection of Kaposi sarcoma associated herpesvirus in peripheral blood of HIV-infected individuals and progression to Kaposi's sarcoma. Lancet 1995;346:799-802.

20. Bigoni B, Dolcetti R, de Lellis L, et al. Human herpesvirus 8 is present in the lymphoid system of healthy persons and can reactivate in the course of AIDS. J Infect Dis 1996;173: $542-9$.

21. Yang GC, Brooks JJ, Roberts S, Gupta PK. The detection of acquired immunodeficiency syndrome-associated Kaposi sarcoma cells in pleural effusion by CD34 immunostain. Cancer 1993;72:2260-5.

22. Ascoli V, Sirianni MC, Mezzaroma I. HHV-8 in lymphomatous and nonlymphomatous body cavity effusions developing in Kaposi's sarcoma and multicentric Castleman's disease. Ann Diagn Pathol 1999;3:357-63.

23. Bedrossian CWM. Malignant effusions. A multimodal approach to cytologic diagnosis. New York: Igaku-Shoin, 1994.

24. Emmert-Buck MR, Bonner RF, Smith PD, Chuaqui RF, et al. Laser capture microdissection. Science 1996;274:998-1001.

25. Otsuki T, Kumar S, Ensoli B, et al. Detection of HHV-8 DNA sequences in AIDS-associated extranodal lymphoid malignancies. Leukemia 1996;10:1358-62.

26. Segal GH, Jorgensen T, Scott M, Braylan RC. Optimal primer selection for clonality assessment by PCR analysis: II. Follicular lymphomas. Hum Pathol 1994;25:1276-82.

27. McCarthy KP, Sloane JP, Kabarowski JH, et al. A simplified method of detection of clonal rearrangements of the T-cell receptor-gamma chain gene. Diagn Mol Pathol 1992;1:173-9.

28. Beck JM. Pleural disease in patients with AIDS. Clin Chest Med 1998;19:341-9.

29. Saville MW, Foli A, Yarchoan R. Antiproliferative activity of TNP-470 (AGM-1470), a novel angiogenesis inhibitor, in Kaposi's sarcoma (KS)-related spindle cell lines. Clin Res 1993; 41:161A.

30. Corbeil J, Evans LA, Vasak E, et al. Culture and properties of cells derived from Kaposi sarcoma. J Immunol 1991;146: 2972-6. 
31. O'Brian RF, Cohn DL. Serosanguinous pleural effusions in AIDS-associated Kaposi's sarcoma. Chest 1989;96:460-6.

32. Costes V, Faumont N, Cesarman E, et al. Human herpesvirus-8-associated lymphoma of the bowel in human immunodeficiency virus-positive patients without history of primary effusion lymphoma. Hum Pathol 2002;33:846-9.

33. Teruya-Feldstein J, Zauber P, Setsuda JE, et al. Expression of human herpesvirus- 8 oncogene and cytokine homologues in an
HIV-seronegative patient with multicentric Castleman's disease and primary effusion lymphoma. Lab Invest 1998;78:1637-42.

34. Jones KD, Aoki Y, Chang Y, et al. Involvement of IL-10 and viral IL-6 in the spontaneous growth of Kaposi's sarcoma herpes virus-associated infected primary effusion lymphoma cells. Blood 1999;94:2871-9.

35. Cesarman E, Mesri EA. Virus-associated lymphomas. Curr Opin Oncol 1999;11:322-32.

\section{Book Review}

\section{loachim HL, Ratech H: loachim's Lymph Node Pathology, Third Edition, 640 pp, Philadel- phia, Lippincott Williams \& Wilkins, 2002 (\$199.00).}

In the field that has been dominated by pathbreaking technical innovations, consensus seeking committees, and multiauthored but often unread textbooks, this "medium-sized book" is almost an anomaly. Developed as a one-man overview of lymph node pathology, it has survived 20 years through three editions as a testament to the lone ranger spirit of its author. It shows that personal opinions still count and that pathologists are still willing to pay for books written by somebody who holds such an opinion; even in the often confusing arena of lymphoma diagnosis, or, maybe, just because this aspect of diagnostic pathology is so confusing.

Like the previous editions, the present one deals with both neoplastic and non-neoplastic diseases affecting the lymph nodes. The old format, based on a systematic, straight-forward presentation of pathologic entities, has been retained, and the emphasis is still on morphology, microscopic diagnosis, and the differential diagnosis. A co-author (Dr. Ratech), well versed in intricacies of modern hematopathology, has been recruited to help update the text and provide a new dimension. The revision of the old text is complete, and the third edition provides a good state-of-the-art snapshot of lymph node pathology. Most illustrations have been replaced by new color microphotographs. Color was added even to the well-known checklists designed for a quick overview of each chapter and a convenient source of salient diagnostic facts. Advances in immunochemistry, flow cytometry, cytogenetics, and molecular biology have been integrated with classic morphology. This has led to a profusion of acronyms, abbreviations, codes, and inevitable CD numbers. However, to the authors' credit, even this alphabet soup is not as thick as it could have been in the hands of less reasonable cooks, or cholilleh, an international task force. The fact that the book is readable and relatively short should make it attractive to many practicing pathologists in need of a dependable, but not overwhelming, reference.

This book, with a proven track record, has been popular with diagnostic pathologists in the last two decades of the 20th century. Its latest edition definitely deserves the attention of the new trainees and even those beyond the formal training period who are still trying to develop a solid understanding of lymph node pathology.

\section{Ivan Damjanov \\ University of Kansas School of Medicine Kansas City, Kansas}

